\title{
PENGARUH GEJALA PARIWISATANISASI REVITALISASI TEPIAN SUNGAI SEKANAK TERHADAP KARAKTERISTIK BANGUNAN DAN KAWASAN HERITAGE SEBAGAI POTENSI URBAN HERITAGE TOURISM DI PALEMBANG
}

\author{
Rizka Drastiani', Dessa Andriyali Armarieno, Sri Liliati \\ Arsitektur, Fakultas Teknik, Universitas Sriwijaya, \\ Jl. Palembang - Prabumulih KM.32 Kabupaten \\ Ogan Ilir, Sumatera Selatan
}

\begin{abstract}
ABSTRAK. Wisata sejarah saat ini merupakan segmen pertumbuhan potensial untuk pariwisata perkotaan. Sejak beberapa tahun belakangan wisata sejarah menjadi salah satu cara untuk meningkatkan ekonomi kembali sebuah kota yang tentunya dengan tidak lupa mengangkat nilainilai lokal untuk diikutsertakan dalam perkembangan wisata sejarah tersebut. Sekanak yang merupakan salah satu kawasan bersejarah di kota Palembang berada tepat di tepian sungai Musi, kawasan bersejarah Sekanak khususnya di sepanjang sungai Sekanak dilakukan perubahan tema lansekap dengan konsep yaitu mewarnai bangunan dan elemen hardscape di sepanjang koridor sungai Sekanak. Apabila disesuaikan dengan kaidah dasar pelestarian kawasan bersejarah. Penelitian ini merupakan penelitian yang bertujuan untuk mengidentifikasi pengaruh pengecatan warna warni bangunan dan bantaran sungai Sekanak terhadap karakteristik kawasan Sekanak Palembang. Metode penelitian yang digunakan adalah metode penelitian deskriptif kualitatif dengan mengumpulkan data-data primer melalui observasi dan data sekunder dari studi literatur dan studi dokumen. Analisis yang dilakukan adalah dengan melihat elemen variabel standar bangunan dan kawasan yang masuk dalam syarat teori pelestarian sehingga dapat dinyatakan bangunan dan kawasan tersebut merupakan kawasan heritage kemudian akan dilakukan studi mengenai kesesuaian pengecatan kawasan tepian sungai Sekanak dengan karakteristik kawasan yang telah diperoleh sebelumnya.
\end{abstract}

Kata kunci: Wisata, Kota, Pariwisata, Sejarah, Sekanak.

ABSTRACT. Historical tourism is a potential growth segment for urban tourism. Since the past few years, historical tourism has become one of the ways to improve the economy of a city, of course by not forgetting to raise local values to be included in the development of historical tourism. Sekanak which is one of the historical areas of the city is located right on the banks of the Musi River, the historic neighborhood along the Sekanak river is done by changing the landscape with a concept made by studying buildings and hardscape elements along the Sekanak river. It is a fundamental principle of preserving the historic area. This research aimed at examining the characteristics of buildings and the banks of the characters of the Palembang area. The research method used by collecting primary data through collection and secondary data from literature studies and document studies. The inheritance area and surveys will be carried out on a standard variable. The inheritance area and studies had been carried out based on the suitability of the Sekanak river bank with the preservation area previously obtained.

Keywords: Tour, City, Tourism, Heriage, Sekanak

\section{PENDAHULUAN}

Kawasan Sekanak dahulunya merupakan kawasan perdagangan yang sangat aktif dan berperan penting bagi kota Palembang. Sebelum masa pemerintahan Belanda tepatnya masa Kesultanan Palembang, etnis Tionghoa tidak boleh mendirikan bangunan diatas tanah, sehingga munculah sejarah rumah rakit, dimana rumah tersebut kebanyakan dihuni oleh etnis Tionghoa. Namun, pada masa pendudukan Belanda, etnis Tionghoa sudah lebih bebas untuk bisa berniaga dan mendirikan bangunan diatas tanah pribumi.
Pasar Sekanak menjadi cikal bakal awal mula terjadinya perniagaan di daratan dan mejadi pasar pertama di darat, kemudian mulai muncul istilah rumah toko atau disebut juga shophouse yang lokasinya berdekatan dengan Pasar Sekanak, sebagian masyarakat ada yang menjadikannya rumah sekaligus toko, sebagian lagi menjadikannya tempat berdagang, sedangkan untuk bermukim sebagian lebih memilih di seberang ulu atau ada juga yang tetap diatas rumah rakit.

Kawasan Sekanak secara tidak langsung menjadi kawasan yang ramai didominasi oleh aktivitas perdagangan terutama pada masa 
pendudukan Belanda di Palembang. Letak kawasan Sekanak dekat sekali dengan sungai Musi yang dahulu menjadi urat nadi jalur transportasi air dan area aktivitas perekonomian dan perdagangan. Hal ini dibuktikan selain dengan adanya pasar Sekanak dan shophouse disepanjang kawasan Sekanak, terdapat juga bekas kantor cabang dagang ekspor-impor Belanda yang bernama Jacobson Van den Berg dan beberapa bangunan peninggalan Belanda lainnya di beberapa titik yang posisinya sangat dekat dengan kawasan Sekanak, sungai Musi dan anak sungai Musi yaitu sungai Sekanak. Sungai Sekanak yang terhubung langsung dengan sungai Musi, dapat dikategorikan sebagai salah satu anak sungai pembentuk morfologi kota Palembang dari awal mula Palembang membangun, yaitu tepatnya pada masa Belanda, sehingga keberadaan sungai Sekanak tidak bisa dilepaskan begitu saja dari konteks dan karakteritik kawasan Sekanak yang di alirinya.

Keberadaan sungai Sekanak saat ini menjadi salah satu potensi wisata menarik untuk di olah sedemikian rupa. Beberapa tahun belakangan wacana dari pemerintah kota yang akan mengembalikan kawasan Sekanak menjadi kawasan heritage dengan konsep Sekanak Kerihin (Sekanak Tempo Dulu) terus digencarkan guna menyambut perhelatan internasional ASIAN Games 2018 di Palembang. Selain menyambut perhelatan tersebut, tujuan paling utama dari revitalisasi kawasan Sekanak adalah menjadikan kawasan tersebut sebagai salah satu destinasi pariwisata. Tahapan awal yang dilakukan oleh pemerintah kota Palembang adalah dengan merevitalisasi kawasan tepian sungai Sekanak yaitu dengan mewarnai bantaran (promenade) sungai Sekanak dengan mural dan warna warna mencolok dengan tema "Sekanak Bersolek".

Mengusung tema "Sekanak Bersolek", kawasan tepian sungai Sekanak di cat dengan menggunakan cat warna-warni, konsep tersebut merupakan adopsi dari konsep kampung warna-warni yang telah dilakukan di beberapa daerah di Indonesia khususnya Malang. Namun kembali lagi, konsep di suatu kota belum tentu bisa diterapkan di kota lain tanpa melihat konteks dan karakteristik dari kawasan yang akan dikembangkan, sehingga kegiatan pariwisatanisasi yang dilakukan pada kawasan tepian sungai Sekanak kedepan mau tidak mau akan mempengaruhi kawasan yang dialirinya dalam hal ini konteks serta karakteristik dan visualisasi kawasan khususnya kawasan bersejarah Sekanak.

\section{METODE PENELITIAN}

Pendekatan studi yang digunakan yaitu studi kasus melalui tahapan

1) melakukan identifikasi pada kawasan Sekanak yang terindikasi sebagai kawasan heritage.

2) memetakan dan mendeliniasikan batasan kawasan Sekanak yang kemungkinan besar terkena dampak revitalisasi sungai Sekanak. Tahapan selanjutnya adalah

3) mengidentifikasi bangunan mana saja yang terindikasi merupakan bangunan cagar budaya/bersejarah,

4) membuat kriteria penilaian dan nilai objek pelestarian pada bangunan dan kawasan secara makro,

5) mengidentifikasi karakteristik kawasan Sekanak dan Sungai Sekanak,

6) mengidentifikasi dampak pariwisatanisasi revitalisasi sungai Sekanak terhadap karakteristik kawasan Sekanak.

\section{METODE PENGUMPULAN DATA}

Pengumpulan data dilakukan melalui studi literatur, materi audio visual, observasi dan wawancara kualitatif. Pengambilan sampel kuali-tatif dilakukan berdasarkan metode sampling purposive atau judgement. Sehingga terpilih beberapa narasumber dalam penelitian ini yaitu ahli sejarah, arkeolog dan ahli cagar budaya selain masyarakat langsung yang menghuni di bangunan atau kawasan tersebut.

\section{METODE ANALISIS DATA}

Penelitian ini menggunakan Metode Analisis Data Kualitatif, dengan melakukan reduksi Data dan Interpretasi Data dengan teknik analisis data dilakukan melalui analisis isi (Content Analysis) dan analisis ringkasan (Summary Anal ysis).

a. Melakukan Identifikasi Makro pesebaran bangunan yang masuk dalam kriteria bangunan cagar budaya dan berpotensi menjadi objek wisata sejarah kota (Urban Heritage Tourism) dan Melakukan penilaian pada objek pelestarian yang telah disesuaikan dengan sebaran bangunan dan deliniasi kawasan.

b. Melakukan kajian terhadap karakteristik kawasan Sekanak dan sungai Sekanak. Melakukan analisis terhadap dampak revitalisasi sungai Sekanak yang telah dilakukan oleh pemerintah dan kemudian 
melakukan overlay dengan kesesuaian kaidah dalam pelestarian dan penataan kawasan heritage.

\section{HASIL DAN PEMBAHASAN}

Sebelum melakukan identifikasi pengaruh gejala "pariwisatanisasi" revitalisasi tepian sungai Sekanak khususnya terhadap karakteristik bangunan dan kawasan heritage Sekanak, hal pertama yang dilakukan adalah memastikan bahwasanya kawasan Sekanak memang merupakan kawasan bersejarah atau heritage, sehingga lebih memperkuat dan mempertegas karakteristik bangunan heritage yang ada didalamnya. Selain itu, diharapkan agar pelestarian kedepannya pada kawasan Sekanak ini lebih memperhatikan nilai-nilai kaidah dasar pelestarian, guna menunjang konsep urban heritage tourism.

\section{Sejarah Perkembangan Kota Palembang [3]}

Kota Palembang telah berumur 1334 tahun. Sebagai sebuah situs kota (urban site), Palembang tentu saja memiliki peninggalan baik benda maupun tak benda salah satunya berupa karya arsitektur sebagai produk peradaban. Sejarah Palembang sebagai kota yang menuju megapolitan secara kronologis dapat diurutkan secara singkat sebagai berikut:

1. Fase I merupakan Fase Awal (682-1365) berdirinya sebuah kota ditandai dengan pembangunan wanua (perkampungan) Sriwijaya pada tanggal 16 Juni 682 Masehi oleh Dapunta Hiyan yang dilanjutkan dengan pembangunan Taman Sriksetra pada tanggal 23 Maret 684 Masehi dan akhirnya perluasan wilayah kekuasaan ke berbagai penjuru (Jambi, Bangka,dan Lampung) era berjayanya kerajaan Sriwijaya .

2. Fase II merupakan Fase Pendudukan (1365-1407) oleh Majapahit atau dapat dikatakan juga Fase Status Quo yang terjadi pada sekitar abad ke- 14 Masehi. Pada masa ini Palembang dalam keadaan tidak terurus dan secara de jure tidak ada penguasa. Berita Tiongkok menyebutkan bahwa pada masa itu Palembang dikuasai oleh orang-orang dari Nan-hai dengan menobatkan Liang Tau-ming bersama putranya sebagai penguasa tertinggi.

3. Fase III merupakan Fase Awal Kesultanan Palembang (1407-1642). Dimulai tahun 1407 ketika Mugni diangkat menjadi raja di Palembang dengan gelar Sultan Palembang. Pada tahun 1445 Mugni kemudian digantikan oleh Aria Damar, seorang bangsawan Majapahit yang memeluk Islam, menjadi penguasa di Palembang setelah berganti nama menjadi Aria Dilah. Pada masa ini Palembang masih berada di bawah pengaruh Jawa (Demak dan Mataram) sampai dengan tahun 1642.

4. Fase IV merupakan Fase Kesultanan Palembang Darussalam (1643-1821) dimulai dari masa pemerintahan Sri Susuhunan Abdurrahman (1643-1651), dan diakhiri pemerintahan Sultan Mahmud Badaruddin II (1811-1821). Pada fase ini, Palembang pada masa pemerintahan Sultan Mahmud Badaruddin I (1724-1758) mengalami pembangunan fisik besarbesaran. Bangunan monumental yang dibuat pada kala itu adalah Keraton Kuto Tengkuruk.

5. Fase V, Masjid Agung Palembang, Makam Kawah Tengkurep, dan Benteng Kuto Besak.Fase V merupakan Fase Pendudukan oleh Belanda yang diawali dengan jatuhnya Benteng Kuto Besak pada tahun 1821. Fase ini berlangsung sampai kemerdekaan tahun 1945. Pada masa ini, bangunan Keraton Kuto Tengkuruk diratakan dengan tanah, dan di atas runtuhannya dibangun rumah Komisaris Belanda. Bangunan ini sekarang menjadi bangunan Museum Sultan Mahmud Badaruddin II. (dalam Drastiani, 2014)

\section{Masa Pemerintahan Kolonial di Palembang $(1821$ - 1945)[4]}

Meski pada dasarnya runtutan cerita sejarah Palembang sudah ada sejak $682 \mathrm{M}$, namun dalam penelitian ini akan lebih dicermati masamasa kedudukan Belanda di Palembang. Dimulainya hubungan dagang antara Belanda dengan kesultanan Palembang sekitar abad 16 - 17. Pada abad ke 19, seorang komisaris yang ditempatkan di Palembang, J.L. van Sevenhoven melukiskan ibu kota Palembang sebagai sebuah kota yang dibagi dan terbagi oleh sungai terbesar di Pulau Sumatra, Sungai Musi. Palembang setelah ditaklukkan Belanda pada 1821 mengalami perubahan yang berarti. Bagi kolonialis Belanda, Kota Palembang sebagai suatu kota air, urat nadi transportasinya adalah sungai dengan memanfaatkan perahu. Belanda mengembangkan kawasan Benteng Kuto Besak sebagai sebagai pusat pemerintahan dan pusat kota. Pada masa ini pula Pemerintah Kolonial Belanda memberi izin bagi penduduk yang tinggal di rumah rakit 
untuk menaikkan rumahnya di atas daratan. Orang-orang Tionghoa, dengan kebijakan ini, banyak yang membangun pertokoan di tanah daratan di pusat perkotaan, umumnya di sekitar Sungai Tengkuruk, yang menjadi cikal bakal Pasar 16 llir dan sekitar Sungai Sekanak yang menjadi cikal bakal Pasar Sekanak.

\section{Sejarah Kawasan Sekanak}

Masa kolonial memiliki nilai sejarah, nilai edukasi, nilai sosial dan nilai ekonomi yang memiliki nilai penting bagi kawasan ini. Seperti yang telah diceritakan sebelumnya, pada masa kolonial sekitar tahun 1821an inilah kawasan Sekanak mulai dibangun. Seperti diberikannya izin masyarakat Tionghoa untuk mendirikan bangunan di darat berupa shophouse, didirikannya pasar Sekanak, gudang boentjit, rumah bola, kantor ledeng, kantor Jacobson van Den Berg dan beberapa bangunan tradisional Palembang.
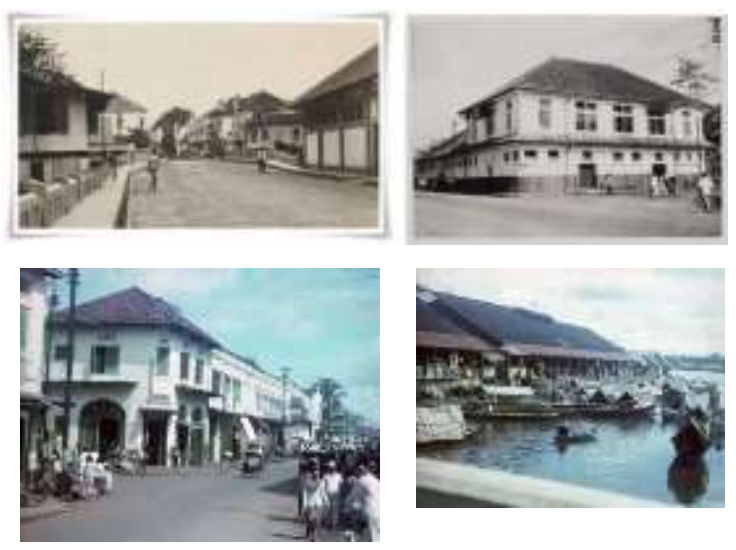

Gambar 1 Photo Kawasan Sekanak Tempo

Dulu sekitar tahun 1920 - 1970an

http://kotapalembang.blogspot.com/2011/[

Selain itu, kawasan Sekanak yang berlokasi kurang lebih 100 meter dari tepian sungai Musi serta anak sungai Musi yaitu sungai Sekanak, menambah nilai sejarah yang lebih bagi kawasan ini.

Bangunan Shophouse pada kawasan Sekanak sebagian besar dihuni oleh etnis Tionghoa, dari awal mula berdiri hingga sekarang. Tahun berdirinya kurang lebih sejak tahun 1921an. Pasar Sekanak didirikan oleh bangsa Belanda berdasarkan sejarah sejak tahun 1821an dan merupakan pasar pertama yang didirikan di daratan.

Bangunan lainnya yang memberikan sumbangsih sejarah dan karakteristik khas di Sekanak yaitu Jacobson van Den Berg, bangunan ini memang belum jelas kapan didirikan di Palembang, namun dipastikan tidak kurang dari 50 tahun telah berdiri. Fungsi awal dari bangunan Jacobson van Den Berg ini adalah sebagai kantor cabang perusahaan Jacobson van den Berg yang bergerak di bidang asuransi dan industri Belanda. Perusahaan ekspor impor Jacobson van den berg menurut sejarah ada di beberapa kota di Indonesia (Semarang, Padang, Batavia, Surabaya, Bandung, Makassar, banjarmasin) juga beberapa negara yang pernah di duduki Belanda, namun untuk Indonesia sendiri, bangunan Jacobson van Den Berg yang masih kokoh berdiri salah satunya di kawasan Sekanak Palembang ini.

Kemungkinan besar alasan didirikannya kantor Jacobson van Den Berg di kawasan Sekanak, adalah karena lokasi Sekanak yang dekat dengan sungai Musi yang pada masanya merupakan satu-satunya jalur transportasi di Palembang.

\section{Deliniasi Kawasan Penelitian}

Sekanak pada fakta di lapangan di jaman ini adalah nama sebuah Jalan, namun pada masa kedudukan Belanda, kawasan ini telah diberi nama kawasan Sekanak, yang terdiri dari persil-persil, sungai dan beberapa Jalan dengan nama berbeda yang salah satunya adalah Jalan Sekanak.

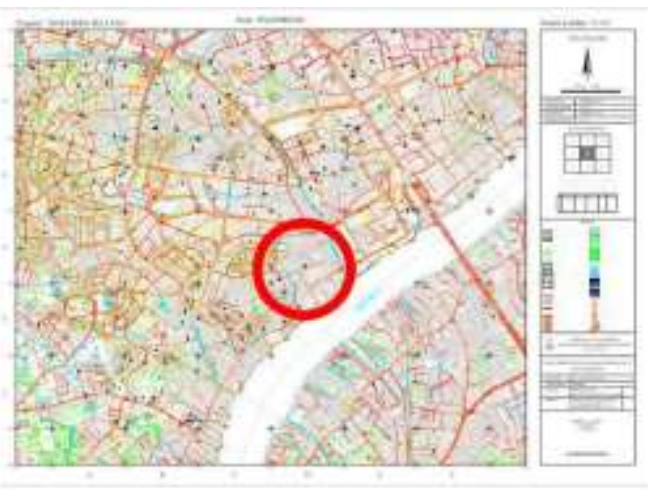

Gambar 2 Peta Kawasan Sekanak,
Palembang
Sumber : Bappeda,Kota Palembang 
Deliniasi kawasan pada penelitian ini adalah sebagai berikut :

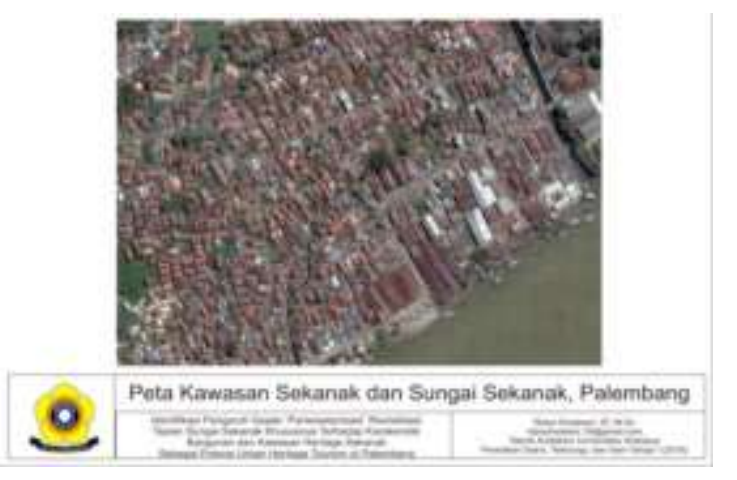

\section{Gambar 3 Deliniasi Peta Kawasan Penelitian Sekanak}

Sumber : Data Peta GIS Kotaku, 2017

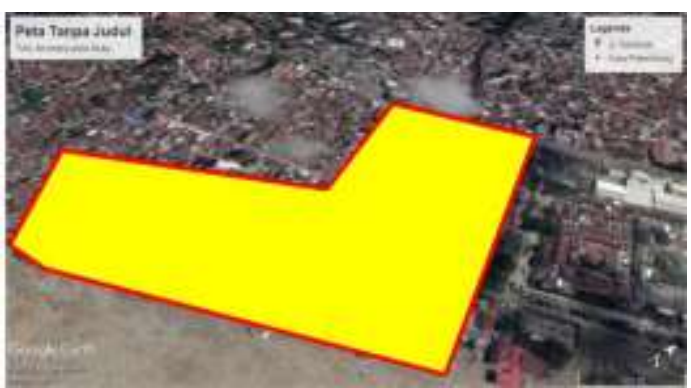

Gambar 4 Deliniasi Kawasan Penelitian Sekanak

Sumber : earth.google.com

Kawasan penelitian lebih diarahkan pada kawasan yang memiliki karakteristik bangunan yang dibangun era kolonial Belanda yang pada saat ini terkena pengaruh pariwisatanisasi warna warni, khususnya pada bantaran sungai Sekanak dan beberapa bangunan di kawasan jalan Sekanak dan kearah jalan Ki Gede Ing Suro.

\section{Identifikasi Pesebaran Bangunan yang masuk dalam kriteria bangunan cagar budaya dan berpotensi menjadi objek wisata sejarah kota (Urban Heritage Tourism) di Kawasan Sekanak}

Berdasarkan dari hasil pendataan dan pedaftaran bangunan yang di duga sebagai bangunan cagar budaya yang dilakukan pada tahun 2016, yang salah satunya dilakukan di kawasan Sekanak terindentifikasi untuk kawasan Sekanak terdapat 44 unit bangunan yang sebagian besar berupa shophouse namun itu diluar beberapa bangunan lainnya seperti Jacobson van Den Berg, Rumah Bola dan Ballroom.

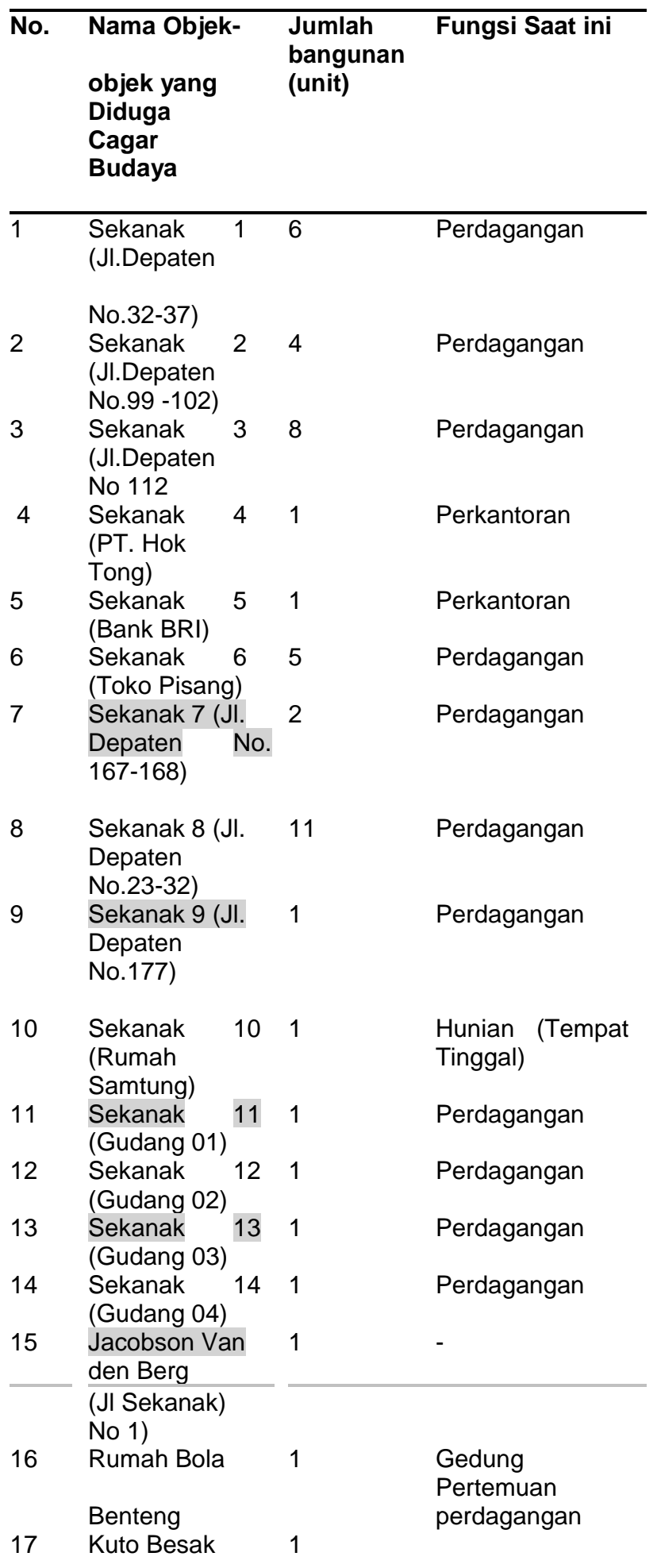

Sumber : Dinas Kebudayaan 2016 


\section{Hasil Penilaian Pada Objek Pelestarian sesuai dengan Deliniasi Kawasan dan Sebaran Bangunan}

Sebagian analisis dalam penelitian ini mengacu kepada piagam burra tentang pelestarian dimana dalam piagam tersebut dinyatakan bahwa terdapat beberapa makna untuk mengetahui nilai penting sebuah kawasan yaitu nilai sejarah, nilai ilmu pengetahuan dan edukasi, nilai budaya, nilai kelangkaan, nilai fungsional, nilai ekonomi, dan nilai sosial. Selain itu, dilakukan pula penilaian berdasarkan beberapa kriteria dalam penilaian kawasan dan bangunan bersejarah berdasarkan Antariksa, 2016 variabel dan indikator yang ada memiliki kesamaan, sehingga dirangkum poin-poin satu sama lain yang dapat dijadikan variabel dan indikator pada penelitian ini, yaitu [1]:

1. Usia Kawasan dan Bangunan

2. Peran Sejarah

3. Keluarbiasaan

4. Memperkuat Citra Kawasan

5. Estetika

6. Keaslian

7. Keterawatan

8. Kelangkaan

9. Kejamakan

\section{Aspek Non Fisik :}

10. Ekonomi

11. Sosial dan Budaya

12. Nilai Pendidikan

Hasil Identifikasi Nilai history kawasan dan Bangunan yang ada di Kawasan Sekanak dan termasuk kawasan tepian sungai Sekanak sebagai pembentuk morfologi kota, dapat terlihat dari hasil identifikasi sebagai berikut : 1). Usia Kawasan dan Bangunan, kawasan Sekanak telah ada sejak tahun 1920an, hal ini bermakna kawasan ini telah berusia 50 tahun lebih, begitupula bangunan yang ada di kawasan tersebut, seperti :

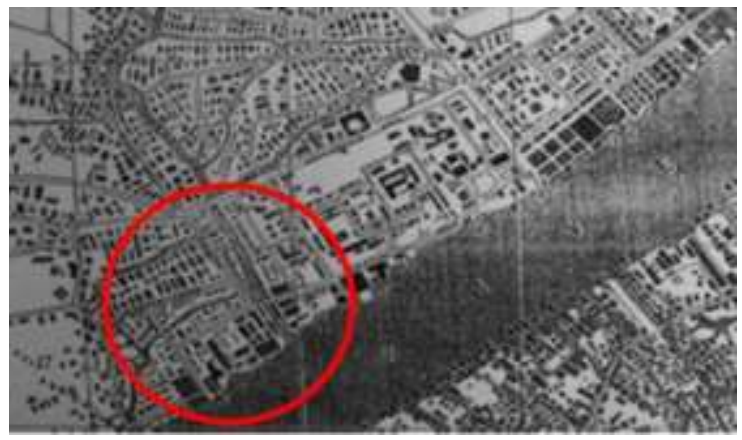

Gambar 5 Peta Kawasan Sekanak Tempo Dulu

Sumber : Dedi Irawanto, Venesia Dari Timur, 2011
- $\quad$ Shophouse tertera tahun 1921

- Jacobson Van den Berg memang belum jelas tahun berdirinya, namun telah ada sejak tahun 1950an

- Pasar Sekanak yang telah ada dari tahun 1920an

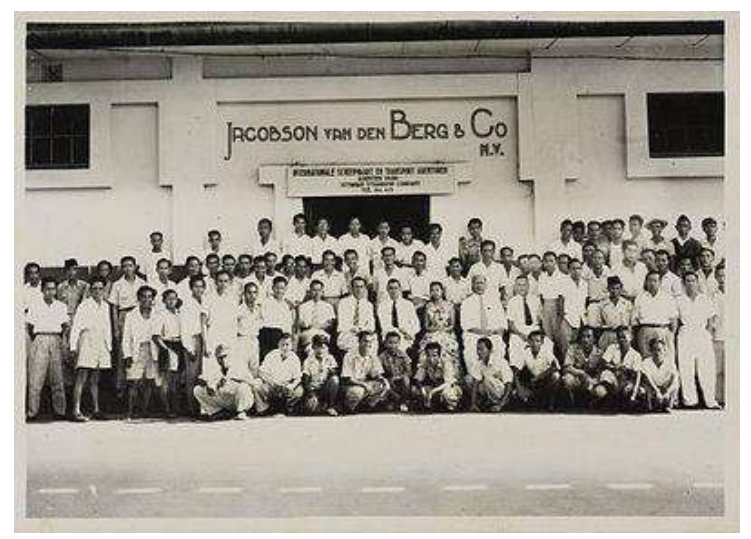

Gambar 6 Kawasan Sekanak Tempo Dulu, tepat di depan bangunan Jacobson Van Den Berg

https://www.google.co.id/search?q=sekanak+t empo+dulu\&safe 
2) Peran Sejarah, Kawasan Sekanak sebagai ikatan simbolis tedahulu dan sekarang, karena telah ada dimasa lalu bahkan sebelum masa kemerdekaan hingga masa moderen saat ini.

- Perkembangan Kawasan Sekanak dimulai dari tahun 1821 saat Belanda mulai memperbolehkan warga Tionghoa untuk mendirikan bangunan di darat.

- Memiliki peran sejarah dalam berkembangnya akulturasi arsitektur kolonial dan arsitektur Tionghoa.

- Sungai Sekanak sebagai anak sungai Musi merupakan salah satu elemen pembentuk morfologi kota Palembang

3) Keluarbiasaan, Sekanak sebagai salah satu pusat perkembangan sejarah kota Palembang, terdapat banyak node-node bangunan dengan arsitektur masa peninggalan Belanda, arsitektur tionghoa dan perpaduan keduanya, Tionghoa dengan kolonial serta arsitektur tradisional

4) Memperkuat Citra Kawasan, Kawasan Sekanak baik dahulu hingga sekarang menjadi kawasan yang telah identik dengan kawasan lama Palembang, sehingga memberikan pengaruh terhadap citra kawasan dan Kota Palembang.

5) Estetika, lebih kepada keunikan kawasan sebagai pembentuk struktur ruang kota yang otentik dan khas dengan bangunan berarsitektural kolonial, berarsitektur perpaduan Tionghoa dan Kolonial dan arsitektur tradisional, yang masingmasing memiliki ciri khas tersendiri.

6) Keaslian Bentuk, dalam hal kawasan tidak banyak berubah dari awal berkembangnya, begitupula bangunan yang ada seperti shophouse bahkan masih ada tertera tahun 1921, dan bangunan Jacobson van Den Berg meskipun saat ini tidak digunakan, .

7) Keterawatan, bangunan yang ada pada kawasan ini $80 \%$ masih terjaga keasliannya.

8) Kelangkaan, dari semua kawasan yang ada di kota Palembang, kawasan Sekanak memiliki bangunan-bangunan dan keunikan tersendiri, mulai dari kawasan yang merupakan kawasan perdagangan dekat dengan tepian sungai, dan bangunan shophouse dengan ornamen dan bentuk yang khas pada beberapa bangunan.

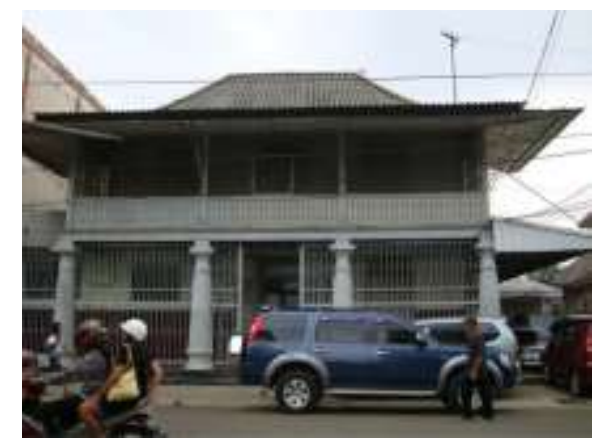

\section{Gambar 7 Bangunan Limas yang memiliki akulturasi Belanda dan Tionghoa Sumber : Dokumentasi Pribadi, 2018}

9) Kejamakan, seperti yang telah dijelaskan pada bagian pendahuluan, bahwa kawasan ini identik dengan kawasan yang banyak dihuni oleh etnis tertentu dan berbaur dengan penduduk lokal. Etnis tionghoa dan penduduk asli Palembang banyak dijumpai pada kawasan ini.

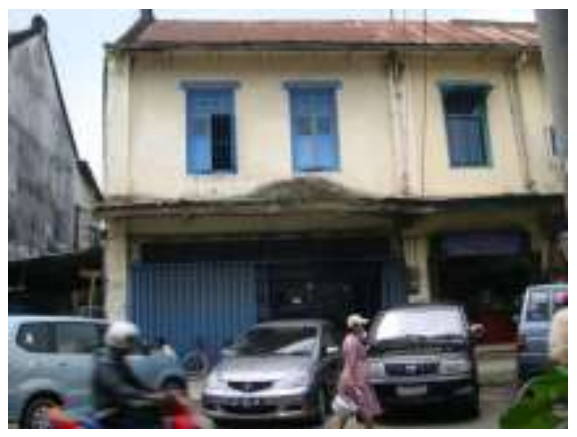

Gambar 8. Bangunan Shophouse masyarakat Tionghoa, di Sekanak

Sumber : Dokumentasi Pribadi, 2018

10) Ekonomi, dengan adanya bangunan bersejarah didalam kawasan bersejarah, dan ditambah dengan kondisi yang masih dikategorikan terawat, kawasan ini dahulu menjadi kawasan padat dan sibuk bahkan di masa sekarang, apabila dilakukan pengembangan kawasan menjadi kawasan wisata bersejarah, dengan menentukan pengembangan yang tepat dan desain yang benar akan semakin menambah nilai ekonomi kawasan ini bahkan bagi kota Palembang.

11) Sosial dan Budaya, kawasan Sekanak menjadi sebuah kawasan akulturasi dan 
saksi sejarah perkembangan kota Palembang yang masih ada sampai saat ini, hal ini menunjukkan secara tidak langsung keberadaan dan jati diri kota yang telah ada dari jaman dahulu hingga sekarang, bahkan di era yang moderen, kawasan dan bangunannya tetap kokoh berdiri.

12) Nilai Ilmu Pengetahuan

- Sebagai kawasan yang masuk dalam fase tahapan perkembangan kota, Sekanak memberikan nilai ilmu pengetahuan khususnya di era kolonial Belanda.

- Memiliki potensi informasi dalam mengungkap lebih luas dan mendalam mengenai sejarah kedudukan bangsa Belanda dan berkembangnya shophouse khas etnis Tionghoa di Palembang.

- Memiliki nilai pendidikan yang tinggi mengenai awal perkembangan masa arsitektur kolonial dan akulturasinya.

- Sungai Musi yang menjadi jalur perdagangan sejak masa lalu dan medan pertempuran di tahun 1821 sehingga memiliki potensi lokus penelitian arkeologi yang tinggi.

\section{Karakteristik Kawasan Sekanak dan Sungai Sekanak}

- Karakteristik Kawasan Sekanak Kawasan Sekanak secara makro masuk sebagai kawasan perdagangan dan jasa dan juga CBD kota Palembang. Kawasan Sekanak memiliki karakteristik yang sangat unik dan kaya baik berupa gaya arsitektur dan nilainilai sejarah dan budaya yang ada. Menurut teori
Shirvani, untuk mempermudah dalam mengetahui karakterikstik kota yaitu dengan cara mengidentifikasi 8 elemen yaitu [8] :

\section{Land Use (Tata Guna Lahan )}

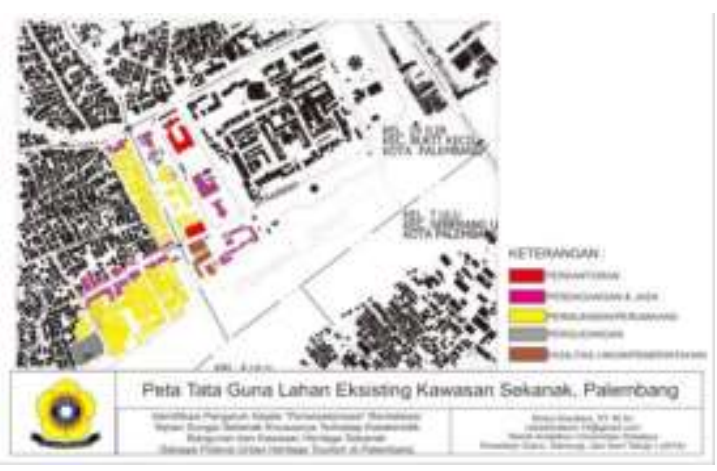

Gambar 9. Land Use

Kawasan Sekanak beberapa bangunan berfungsi sebagai permukiman/perumahan masyarakat asli Palembang dan peranakan, kawasan komersial, perdagangan dan jasa, pergudangan, perkantoran, dan fasilitas pemerintahan.

\section{Building form and Massing \\ G Gaya Arsitektur}

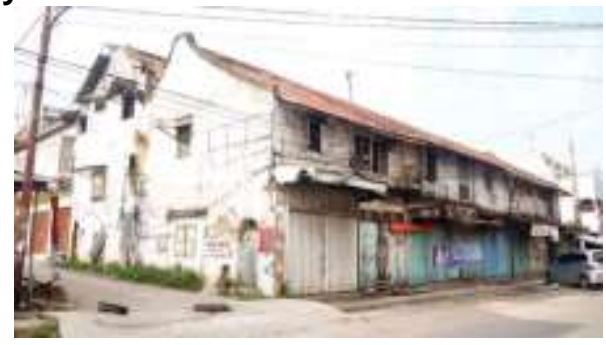

Gambar 10 Bangunan Shophouse Bergaya Arsitektur Kolonial milik etnis Tionghoa dengan atap bergaya Ngang Shan The Sumber : Hasil Identifikasi, 2018

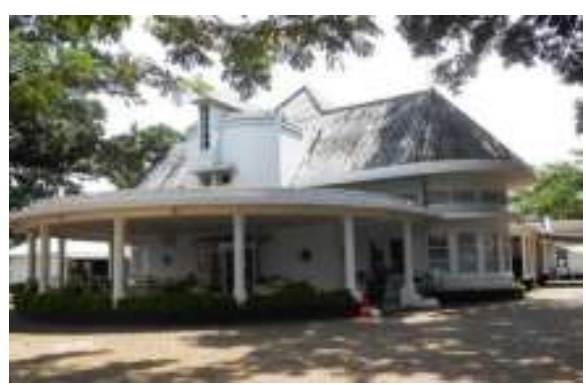

Gambar 11. Bangunan Bergaya Arsitektur Art Deco

Sumber : Hasil Identifikasi, 2018 
Gaya bangunan yang ada di kawasan Sekanak dibagi menjadi beberapa jenis yaitu bangunan bergaya kolonial, Pecinan dan tradisional Palembang.

\section{Solid dan Void}

Density bangunan di kawasan Sekanak cukup tinggi, khusus berupa shophouse memiliki tipikal berdempetan satu dengan lainnya. Namun, khusus bangunan kolonial kebanyakan memiliki massa tunggal dengan ketinggian beragam.

\section{Sirkulasi dan Parkir}

$\square$ Sirkulasi pada kawasan ini terdiri dari jalur sirkulasi daratan berupa jalan-jalan utama dan jalan lingkungan dan jalur sirkulasi sungai.

$\square$ Parkir pada kawasan ini terbagi 2, yaitu parkir kendaraan bermotor yang ada di darat dan parkir kapal dan perahu di tepian sungai. Sebagian besar parkir kendaraan di daratan masih berupa on street parking yaitu parkir di badan jalan. Untuk parkir kapal dan perahu masih belum tertata dan belum sesuai standar.

\section{Pedestrian Ways}

Kawasan Sekanak secara keseluruhan sangat minim kelayakan jalur pejalan kaki, padahal kawasan ini sangat potensial untuk dijadikan kawasan yang ramah pejalan kaki.

\section{Open Space}

Area terbuka pada kawasan sekanak yang potensial banyak terdapat di bantaran tepian sungai Musi dan sungai Sekanak.

\section{Activity Support}

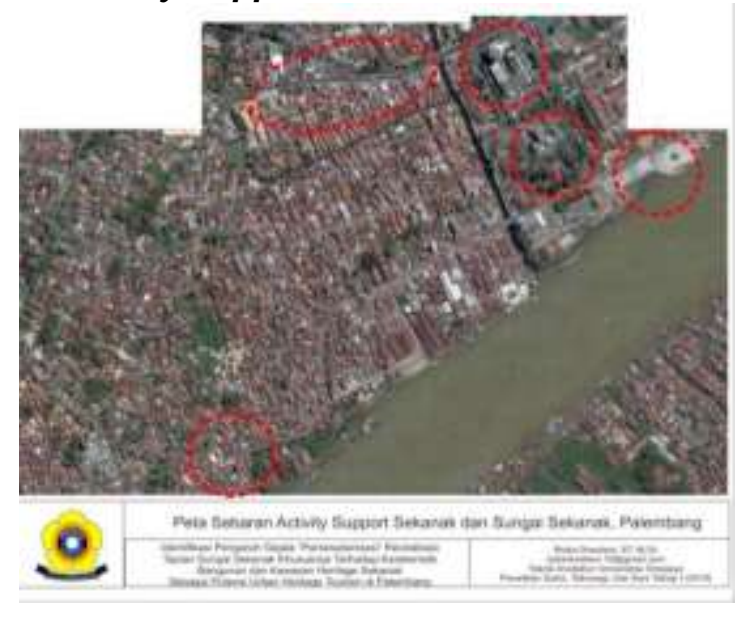

Aktifitas penunjang kawasan yang paling utama adalah kawasan perkantoran Walikota (Kantor Ledeng), kawasan perdagangan dan jasa baik shop house (ruko sepanjang jalan
Sekanak), Pasar Sekanak, Kampung Kuliner Pempek, aktivitas wisata tepian sungai Musi dan Benteng Kuto Besak.

\section{Presevasi}

Banyak sekali terdapat bangunan peninggalan era kolonial dan pasca kemerdekaan, serta bangunan tradisional Palembang yang terindikasi cagar budaya (bersejarah). Beberapa bangunan diantaranya adalah shophouse sepanjang jalan sekanak menuju jalan Ki Gede Ing Suro, bangunan kolinial yaitu Jacobson van Den Berg, Balai Prajurit, restoran Benteng Kuto Besak, termasuk pula kantor walikota Palembang.

\section{Signage}

Signage khususnya papan reklame pada kawasan Sekanak belum tertata dan belum memiliki standar ukuran yang baik.

\section{Karakteristik Kawasan Tepian Sungai Sekanak}

Sungai Sekanak yang merupakan anak sungai Musi, mengalir membelah kawasan Sekanak. Keberadaan sungai Sekanak tidak bisa dilepaskan dari perkembangan morfologi kota Palembang. Sungai Sekanak tepat membelah di antara kawasan Sekanak, diantara bangunan bersejarah kota Palembang, seperti pasar Sekanak, bangunan Jacobson Van Den Berg dan kawasan kantor Ledeng yang dahulunya dibangun oleh Belanda. Sungai Sekanak dari era kolonial hingga saat ini masih terus mengalir dan merupakan salah satu sungai yang tidak dipilih Belanda untuk dilakukan penimbunan. Hal tersebut kemungkinan besar memiliki alasan yang cukup penting bagi perkembangan morfologi kota Palembang.

Sungai Musi dan sungai Sekanak sebagai elemen urban waterfront, yang memiliki makna sebagai suatu lingkungan perkotaan yang berada di tepi atau dekat wilayah perairan, juga dapat dikategorikan sebagai urban heritage waterfront [4]. Latar belakang historis kawasan Sekanak sangat dipengaruhi dengan keberadaan sungai Musi dan sungai Sekanak sebagai anak sungai Musi. Hal inilah yang membuat kawasan Sekanak ini dapat dikategorikan sebagai kawasan waterfront.

Pada peneliatian ini akan lebih di fokuskan pada dampak pariwisatanisasi revitalisasi sungai Sekanak, untuk itu akan dibahas mengenai karakteristik kawasan tepian air. Karakteristik kawasan tepian sungai Sekanak dapat dilihat dari beberapa aspek, menurut Torre (1989), ada beberapa aspek yang 
penting dalam suatu kawasan waterfront antara lain [8]:

\section{Tema (Theme)}

Kawasan tepian sungai Sekanak pada dasarnya memiliki kekhasan yang spesifik terutama dari segi sejarah dan sosial budaya. Kondisi dan iklim di kota Palembang dapat memberikan ke otentikan yang seharusnya berbeda dan menimbulkan sense of place dari pada wilayah lain yang sama-sama memiliki potensi waterfront.

\section{Fungsi (Function)}

Sepanjang tepian sungai Sekanak dilakukan revitalisasi, perencanaan revitalisasi sungai sekanak yang bertujuan untuk menjadikan kawasan tepian sungai ini agar lebih memiliki nilai jual wisata sehingga memberikan dampakdalamsegalabidang khususnya bagi masyarakat setempat, sudah tepat, namun tetap harus disesuaikan dengan karakteristik dan konteks tepian kawasan dan sungai itu dimana berada.

\section{Citra/Visual (Image)}

Visual dalam hal ini berkaitan pula dengan citra dan image kawasan tepian sungai. Untuk hal fungsi dapat berupa aktivitas tepian air, sementara dari segi visual hal ini berpengaruh terhadap tampilan fisik baik berupa desain, warna dan keselarasan dengan bangunan dan lingkungan sekitar. Pada dasarnya kawasan Sekanak yang dialiri sungai Sekanak adalah kawasan prestisius yang memiliki nilai sejarah yang tinggi. Sungai Sekanak merupakan satu elemen pendukung pembentuk morfologi kota, dari nilai prestisius tersebut, sehingga pengembangan revitalisasinya perlu dipikirkan dan di eksekusi secara tepat dan baik, sehingga dapat memberikan visualisasi yang baik dan memberikan spirit of place bagi kawasan Sekanak.

\section{Pengalaman (Experience)}

Sungai Sekanak perlahan sudah mulai berbenah dengan dilakukannya pengerukan dan membersihkan sampah -sampah. Saat ini, pengembangan revitalisasi sudah pada tahap mencoba untuk memberikan akses dan ruang-ruang bermain ke arah sungai.

\section{Identifikasi Dampak Revitalisasi Sungai Sekanak terhadap karakteristik bangunan dan kawasan Heritage Sekanak.}

Makna mendasar revitalisasi menurut KBB adalah proses, cara, perbuatan menghidupkan atau menggiatkan kembali. Sedangkan menurut UU RI No. 11 Tahun 2010 tentang CB, Psl 1 (31), kegiatan pengembangan yang ditujukan untuk menumbuhkan kembali nilainilai penting Cagar Budaya dengan penyesuaian fungsi ruang baru yang tidak bertentangan dengan prinsip pelestarian dan nilai budaya masyarakat.[9]

Revitalisasi biasanya berkaitan erat dengan pelestarian, sehingga produk-produk hasil revitalisasi semestinya sesuai dengan dasar norma pelestarian.

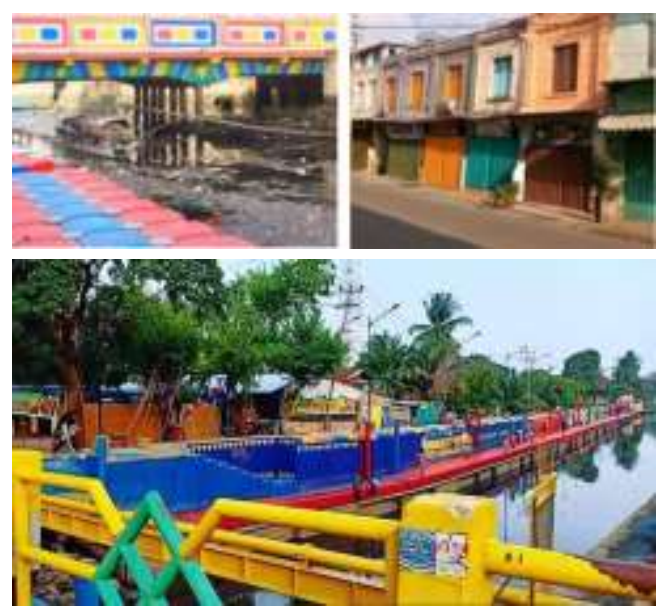

Gambar 12. Foto revitalisasi sungai Sekanak dan bangunan shophouse di Sekanak Sumber : Dokumentasi Pribadi, 2018

Tujuan dari revitalisasi sungai Sekanak salah satunya adalah peremajaan kota yang berdampak pada nilai pariwisata. Pada dasarnya peremajaan kota (urban renewal) sebagai upaya atau pendekatan dalam proses perencanaan guna menata kembali suatu kawasan tertentu dalam kota yang bertujuan mendapatkan nilai tambah yang memadai untuk kawasan tersebut sesuai dengan potensi ekonomi yang dimiliki oleh lahan kawasan.(Danisworo, 1996)[2].

Dengan mengadopsi konsep kampung warna -warni yang ada dibeberapa daerah, amat disayangkan karena pada hakikatnya standar dalam melakukan pengecatan pada bangunan heritage harus disesuaikan dan menggunakan bahan cat dan warna yang sesuai untuk bangunan heritage. 


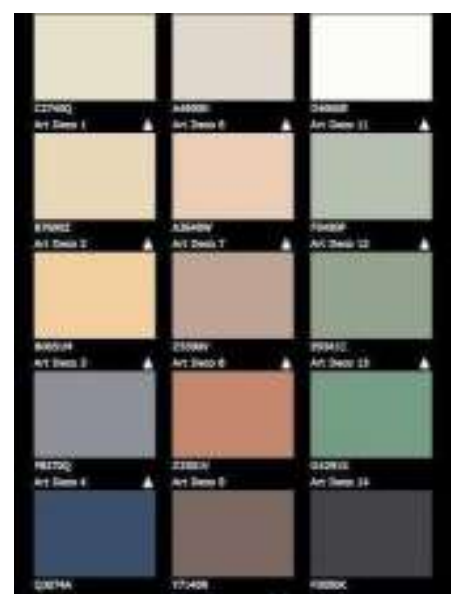

Gambar 13 Jenis dan Warna Cat khusus untuk bangunan heritage

Sumber : Propan Indonesia

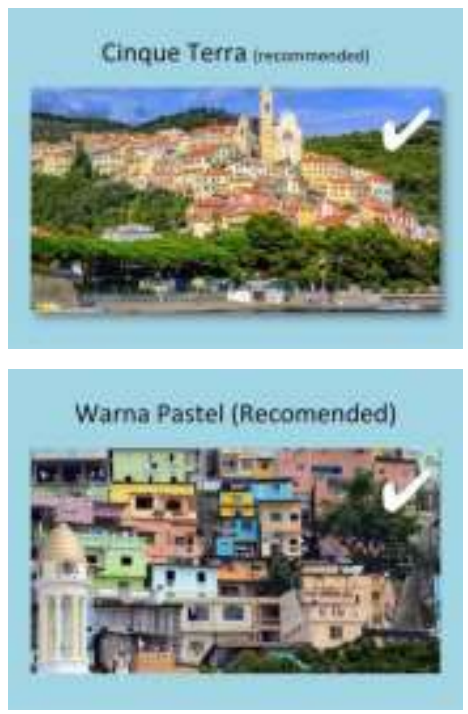

Gambar 14. Rekomendasi Warna pada bangunan Sumber : Analisis Astrid Haryati, Urban Designer 2018

Dari hasil identifikasi yang dilakukan di awal, berupa penilaian kawasan Sekanak dan sungai Sekanak, keduanya merupakan satu kesatuan kawasan yang tidak dapat di pisah dan memiliki nilai sejarah yang tinggi, sehingga pengembangannya perlu disesuaikan dengan kaidah dasar pelestarian. Saat ini revitalisasi sungai Sekanak telah dilaksanakan, namun belum sepenuhnya sesuai dan belum mempertimbangkan secara utuh dari peninggalan artifak arsitektur dan urban site yang ada. Dari pembahasan menyeluruh dapat di identifikasikan dampak positif dan negatif dari "Pariwisatanisasi" Revitalisasi sungai Sekanak, yaitu :

Dampak Positif dari Revitalisasi Sungai Sekanak dapat ditinjau dari segi ekonomi dan segi sosial budaya. Dari Segi ekonomi : a) Pemerintah mulai menyadari potensi kawasan Sekanak sebagai salah satu destinasi wisata.

b) Masyarakat sekitar seharusya menjadi sasaran utama yang memperoleh manfaat dari revitalisasi tersebut.

Dari Segi Sosial Budaya

a) Pemerintah mulai memperhatikan standar kebersihan dan aliran drainase serta pembuangan ke arah Sungai Sekanak dan Kawasan seputaran Sekanak.

b) Perlahan masyarakat di mentoring untuk mulai membenahi dan lebih tertib menyoal tentang kebersihan lingkungan.

Dampak Negatif dari Revitalisasi Sungai Sekanak apabila tidak sesuai dengan kaidah dasar pelestarian. Dari Segi Karakteristik Kawasan dan Bangunan

a) Pengaruh revitalisasi sungai Sekanak dengan konsep mewarnai elemen hardscape bantaran atau sering disebut Dengan konsep revitalisasi kekinian, mengaburkan karakteristik dan citra kawasan dan bangunan di Sekanak sebagai kawasan Heritage.

b) Bangunan Heritage yang masih ada sampai saat ini, terutama bangunan yang belum terjamah untuk dilestarikan, tidak menjadi fokus utama para wisatawan yang berkunjung, sehingga lambat laun makin terbengkalai.

Dari Segi Visual Arsitektur dan Visual Tepian Sungai

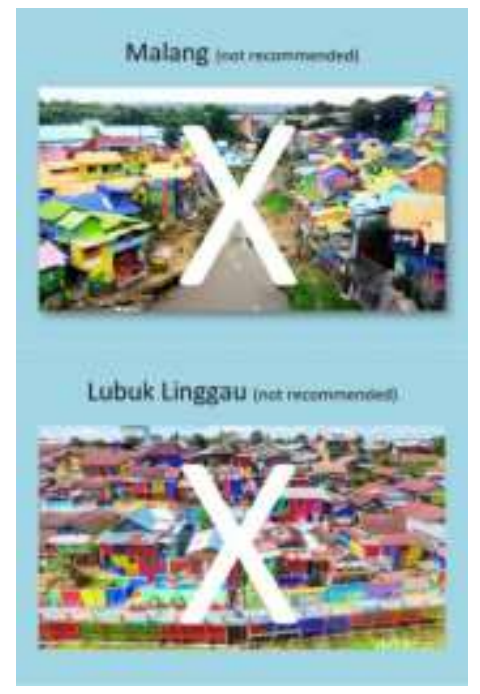

Gambar 15. Tidak Direkomendasikan konsep pewarnaan yang tidak sesuai dengan konteks kawasan

Sumber : Analisis Astrid Haryati, Urban Designer, 2018 
a) Potensi pengembangan kawasan Sekanak yang sebenarnya bisa menjadi urban heritage tourism, saat ini pengembangannya menjadi lebih kearah mewarnai bangunan saja tanpa melihat akar potensi yang sesungguhnya, sehingga terjadi kemonotonan dalam pengembangan pariwisata di kota-kota di Indonesia akibat terlalu banyaknya yang mengadopsi kampung warna warni.

b) Menghilangkan Ciri khas dan Jati diri Kawasan secara khusus dan kota Palembang secara umum sebagai Kota Tertua di Indonesia bahkan masuk dalam kota tertua di dunia.

c) Pengaruh pengembangan warna warni tepian sungai Sekanak dapat berdampak pada bangunan heritage yang berpotensi pula untuk diwarnai dengan penggunaan material cat dan warna yang tidak sesuai.

\section{KESIMPULAN}

Perkembangan pariwisatanisasi di beberapa kota di Indonesia memberikan efek yang signifikan pula bagi pariwisata di kota Palembang. Kampung warna-warni yang akhirakhir ini menjamur dibeberapa kota, ikut pula di adopsi oleh pemerintah Palembang, guna mengembangkan objek pariwisatanya. Kawasan Sekanak yang masuk ke dalam salah satu kawasan pengembangan dan destinasi pariwisata kota, tidak luput dari wabah warna warni, meskipun warna warni yang dilakukan masih di area koridor sungai Sekanak, namun hal tersebut secara tidak langsung memberikan efek bagi nilai sejarah kawasan dan bangunan sejarah yang masih ada hingga saat ini. Selain melakukan pewarnaan pada pedestrian, terdapat juga mural yang dilakukan pada dinding-dinging dan elemen hardscape lansekap kawasan di sekitar Sekanak dan sungai Sekanak.

Revitalisasi yang telah dilakukan sebaiknya pula melihat dan mempertimbangkan kawasan Sekanak secara utuh, bukan hanya sekedar kawasan tetapi juga bangunan-bangunan bersejarah yang masih berdiri kokoh disekitaran kawasan sungai Sekanak. Selain itu diharapkan kedepannya bagi wisatawan yang mengunjungi kawasan dan bangunan di Sekanak, agar bisa melihat Sekanak lebih mendalam khususnya dari segi sejarah perkembangan kota Palembang, sehingga wisatawan memperoleh wawasan dan kesan mendalam dari tempat yang dikunjunginya (sense of place) dan nilai historinya (Spirit of place), dan bukan hanya sekedar menikmati euforia sesaat berupa warna-warni dan mural yang ada. Sebagai sebuah peninggalan sejarah yang ingin tampak lebih modern dan kekinian, stakeholder dan masyarakat yang terkait agar lebih di edukasi mengenai pentingnya nilai sejarah untuk perkembangan sebuah kota, sehingga kedepannya diharapkan revitalisasi kawasan sungai Sekanak yang telah dilakukan saat ini, lebih mengarah dan sesuai dengan kaidah dasar pelestarian dan disesuaikan dengan value sejarah masa lampau, baik dalam hal elemen lansekap kawasan yang berpengaruh kepada bangunan bersejarah yang ada.

\section{DAFTAR PUSTAKA}

[1] Antariksa. (2016). Teori dan Metode Pelestarian Kawasan Pecinan. Cahaya Atma Pustaka.

[2] Danisworo. (1996). Penataan Kembali Pusat Kota: Suatu Analisis Proses. Journal of Regional and City Planning $\begin{array}{llll}\text { Vol } & 7 & \text { No } & \end{array}$ http://journals.itb.ac.id/index.php/jpwk/articl e/view/4409

[3] Data Bangunan Cagar Budaya di Kawasan Sekanak, Dinas Kebudayaan Kota Palembang. (2016)

[4] Drastiani, Rizka. (2014).

Pengembangan Kawasan Tangga Buntung sebagai Creative Cluster Industry di Kawasan Wisata Tepian Ilir Sungai Musi Palembang

[5] Irwanto,Dedi Muhammad Santun. (2011). Venesia Dari Timur: memaknai produksi dan reproduksi simbolik kota Palembang dari colonial sampai pascakolonial. Penerbit Ombak Palembang.

[6] Peta Sekanak, BAPPEDA Kota Palembang

[7] Peta GIS Kawasan Sekanak. (2017). Kotaku

[8] Piagam Pelestarian Pusaka Indonesia. (2003). Merayakan Keanekaragaman.

[9] Shirvani, Hamid. (1985). The Urban Design Process. Van Nostrand Reinhold, New York

[10]Torre, L Azeo. (1989). Waterfront Development. Van Nostrand_Reinhold, New York

[11] Undang-undang No.11 Tahun 2010 Tentang Cagar Budaya

[12] http://kotapalembang.blogspot.com /2011/

[13] https://www.google.co.id/search?q=se kanak+tempo+dulu\&safe 